\title{
Making sense of climate change: orientations to adaptation
}

\author{
Timothy Lynam $^{1,2,3}$ and Iain Walker ${ }^{4,5}$
}

\section{INTRODUCTION}

Good stories are hard to find in academic journals. In books we find them: thrilling accounts of voyage and discovery where characters take shape in our minds and perhaps even touch our hearts lest we leave them aside. Wade Davis's account of Richard Schultes's work in the Amazon is like that (Davis 1996). But emotions are not supposed to shape our science, the stuff we publish in journals. These crisp little gems of peer guaranteed truth should simply modify what we know and perhaps cunningly compel us to faithful reproduction of some meme or other. But move us to joy, frustration, or anger? Leave us empathizing with a particular character? No, that shouldn't really happen. Just give us the briefest possible account and move on because that is what science is concerned with: the briefest possible account of reproducible facts. But underpinning every scientific paper are dozens of stories: of how the ideas formed; of how things were done and evolved; of how the papers and ideas therein came to take just that form; and of the people back there in the forensic scape of words, numbers, and images whose characters so infuse the science and the resulting papers but remain obscure.

The idea of "just give us the reproducible facts" is starkly at odds with so much very good science that tells us that process matters to outcomes, so do people and situations; that science cannot be divorced from the social realities in which it emerged, unfolded, and in which it is subsequently told; and that the outcome of science may be as much a function of the people involved, their frames of reference, and the situations they had to contend with in getting funding, conducting the science, and publishing that paper as the data and data collection processes described in the paper. This evidence is so compelling that we would like to briefly tell you the story of this special feature, the context in which it emerged, what it looked like in our original vision, and how different that is to what you can now read. We want to share our experiences with you in case you are tempted to do something similar. And of course we hope you will be.

Undeniably the papers of this special feature have their own stories to tell: the scientific stories, the ones we are used to reading in scientific journals. In the second section of this editorial we focus on the published papers and seek to synthesize what they tell us about people making sense of climate change and how this orients them to adaptation. In so doing we seek to highlight contextually relevant patterns in what the papers say.

In our story of this special feature we describe how many of the possible accounts and papers fell by the way side for one reason or another. And of course we did not know at the beginning what we have learned along the way. Therefore, in the final section we highlight some of the things we have learned as well as some of the things we wish we now knew and hope they might intrigue others so more stories can be told of the many facets of how the social and individual processes of making sense of climate change orient people to adaptation!

\section{A PROCESS STORY}

In late 2009 / early 2010 members of the mental models working group within the Resilience Alliance were developing the papers that would form the basis of the first special feature in the mental models working group series (Lynam and Brown 2011). The research reported in that special feature sought to test two approaches to eliciting mental models with the key learnings articulated in most papers of the special feature (Jones et al. 2011, Lynam and Brown 2011, Mathevet et al. 2011, Stone-Jovicich et al. 2011) and in a synthesis paper (Lynam et al. 2012). One of the key recognitions of that body of work was the importance of human narrative in how people thought about and communicated ideas. But neither of the methods used to elicit mental models was up to the task of working with narrative. Complex issues were broken down into sparse statements or terms and then we looked for relationships among those. But we knew people did not think or converse using single words or sparse phrases: they talked and thought in sentences and stories! We also recognized the importance of situations in the formation and articulation of cognitions of environmental issues. These ideas motivated Natalie Jones to do her PhD on examining different elicitation devices in situated and abstracted contexts. Although her sample was small the results were striking: situation made a huge difference to the number and type of concepts that were elicited (Jones et al. 2014). We had evidence to show that situation was important but still did not have a method that enabled us to use narrative.

Enter Cognitive Edge's intriguing software suite, SenseMaker (Cognitive_Edge, http://cognitive-edge.com/sensemaker/). Harry Biggs, one of the original mental models working group members, suggested we look at SenseMaker, so we quickly immersed ourselves in David Snowden and Cynthia Kurtz's published work (Kurtz and Snowden 2003, Snowden and Boone 2007) and found someone to demonstrate what SenseMaker could do. Chris Fletcher of Emerging Options demonstrated SenseMaker's capabilities and later trained some of us in its use. We were hooked: this looked to be exactly the tool we needed to explore narrative.

A second mental models group was formed to explore what we might find out about human cognitions using micronarratives. SenseMaker not only enabled us to do what we had been looking to do, i.e., collect narratives, but did it in a way we had not imagined possible: the narrative was only part of the data; respondents also used predefined questions to interpret the narratives they had typed in or related. It was a completely 
integrated mixed methods tool (Lynam and Fletcher 2015) that was underpinned by Cynthia Kurtz and David Snowden's novel ideas on complexity and human sense making.

But we needed more than just a set of tools. We needed theory to guide what we were doing. From the work we had done with the original mental models group we knew that the individual as a cognitive island construct so commonly associated with mental models research just did not fit the data we were seeing: human knowledge structures were very much embedded in and a function of social processes (Mathevet et al. 2011, Stone-Jovicich et al. 2011, Lynam et al. 2012). We turned to social representations theory (Moscovici 1984, Augoustinos et al. 2014), which provided a well-grounded theory base to underpin our proposed use of narrative.

Because several of us were doing research on adaptation to climate change we sought to apply the tool (SenseMaker) to test use of narrative in eliciting human cognitions and specifically cognitions in relation to what enabled and what constrained adaptation to climate change. The details of our three applications of the data collection process are described in the paper by Lynam and Fletcher (2015). The first application was at a climate change adaptation conference in Australia in 2010 and the second was in a Victorian Government department whose mandate included climate change. Kyla Milne from the Climate Change Directorate (now Climate Change Unit or CCU) of the Nova Scotia government heard about our project from a colleague of hers in government who saw an outline of the work on the Cognitive Edge user's network web site that Chris Fletcher had posted. We modified the instrument to make it applicable in Canada and the third implementation was a joint Canadian government / practitioner and Australian general public application.

On completing each application Chris Fletcher presented us with what he called "naïve analyses," analyses done by someone who does not have intimate knowledge of the problem domain. As we started looking we recognized the incredible richness of the data: layers of analysis became possible that we had not imagined. A number of individuals were invited to join the group to analyze all or some of the data applying different tools and theoretical orientations. The central idea of the "project" was to have multiple groups make sense of the same data set from different theoretical or analytical perspectives.

There are many stories that could be told with this sort of endeavor and data as rich as we collected; we have barely scratched the surface of analytical options, theoretical orientations, and storytelling. Quite a few important stories have not been told but really deserve to be, but unfortunately their authors were, for many different reasons, unable to complete their stories for this special feature of Ecology and Society.

\section{THE PAPERS}

Lynam and Fletcher: Sensemaking: a complexity perspective The paper by Lynam and Fletcher (2015) provides a methodological foundation for all the other papers in this special feature. The other papers present insights from different analytical angles on the same novel, large data set. Lynam and Fletcher describe the procedure whereby that data set was produced. In this sense then, Lynam and Fletcher's paper undergirds the other papers, and they should be read in conjunction with this one.

Lynam and Fletcher start with the well-recognized and accepted view that climate change is a dramatic example of a complex or wicked problem, with major implications for human social organization, which is poorly, if at all, understood by the general community. It is little surprise that humans, individually and collectively, have struggled to respond meaningfully to climate change. The challenge for researchers in this domain is to better comprehend how, when, and why humans respond to the complexity and wickedness of climate change. There is, of course, a considerable volume of research that addresses human responses to climate change, but it is probably fair to say that that research has not yet cracked the nut.

Lynam and Fletcher develop a fresh perspective on the problem of human responses to climate change. They turn to the importance of narrative, both as a feature of human social life and as a rich source of insight for understanding human behavior. Humans structure experience through narrative; narrative is a vital element of how humans make sense of what is going on around them (e.g. Sarbin 1986, Weick 1995). They then introduce a model of stages of behavior change (Prochaska and DiClemente 1986, Prochaska et al. 1992) as a framework for systematic analysis of the data on adaptation to climate change.

There are many methods of doing narrative inquiry; all are wellsuited for producing insights into individual experiences, but none lend themselves easily to producing insights into broader patterns of experience across groups or sections of society. Their laborintensity is their primary limiting factor in this regard. Another broad concern is whether the interpretation of a narrative, its meaning, reveals more about the narrator or the researcher. Lynam and Fletcher introduce Sensemaker as a novel method for overcoming these two limitations of narrative inquiry. Sensemaker asks participants to generate a constrained narrative, and then to provide their own interpretation of that narrative in using questions and choices that reflect key dimensions of interest to the researcher.

Lynam and Fletcher's paper presents the methodological details that underpin the other papers in this special feature. They also present the results of their own analysis of the data in the context of stages of change. Using an approach similar to that advocated by Cognitive Edge whereby analyses of respondents' answers to questions about their narratives were used to identify clusters of narratives that were useful in understanding stages of change in relation to climate change adaptation. They find that the number and content of narrative threads are different at each of the four stages of change. This offers a potential lead for researchers and others to pursue in trying to mobilize individual and collective climate adaptation behaviors. The use of Sensemaker was not without issues for Lynam and Fletcher in their study, though.

Finally, they end their contribution with some recommendations for improving or extending their study. Most notable among these is the highlighted need to try to understand the transition probabilities for people moving from one step in the stages-ofchange model to another. We would amplify this point by stressing that this is not just an empirical question, but one that requires 
conceptual development of the stages-of-change model to consider, for example, whether movement through the stages must be done sequentially or whether there can be quantum shifts, and whether and how movement can be in both directions through the stages. These are important practical considerations for researchers and organizations promoting climate adaptation behaviors.

\section{Moloney, Leviston, Lynam, Price, Stone-Jovicich, and Blair: Using social representations theory to make sense of climate change: What scientists and non-scientists in Australia think} The narrative analysis presented in Lynam and Fletcher's paper focuses mostly on individual narratives, analyzed in aggregate. But narratives are never just produced by individuals. Individual narratives are contextualized, informed, and shaped by social or cultural narratives. Narratives are not written by isolated, atomized individuals; the main characters and the plots and subplots are furnished by the social context. This is the focus of the paper by Moloney et al. (2014). The data in this paper are word associations provided by respondents in the same surveys described by Lynam and Fletcher and in surveys conducted by Australia's Commonwealth Scientific and Industrial Research Organisation (CSIRO) as part of a longitudinal analysis of public understandings of climate change (Leviston and Walker 2011).

Moloney and her colleagues situate their analysis within social representations (SR) theory, which provides an account of the social production of shared knowledge, especially in the fraught space between universes of expert knowledge and the domain of common sense. This treats "climate change" as a social object, not as a biophysical reality. They show how the meaning of climate change for groups of scientists, government employees, and community members, has a consensual core, mostly related to weather, but also varies across the three groups. Government employees are different from scientists and community members in their emphasis on planning and adaptation. Scientists seem alone in associating climate change with mitigation and carbon management, which are technical concepts. Community members seem to differ from the other two groups in not necessarily perceiving climate change as anthropogenic. These results have implications for how members of the different groups (and others) might engage with one another, how scientists communicate their findings to government or to the public, for example, or how government employees go about implementing changes in local government practices and policies. Another major implication of the study is that, when engaging with the public, scientists, communicators, and decision makers are mistaken to act as though citizens think and act individually. They do, of course, but more importantly, their thoughts and actions are social. That is, thinking and acting are shared, collective, and interdependent. A final important implication of the Moloney et al. study is that it is mistaken for scientists and policy makers to act as though citizens' knowledge is wrong or incorrect, as assumed by the now much-maligned, but still implicitly common, "knowledge deficit" framework of science communication. Citizens' knowledge is different, not wrong. It can contain errors of fact of course, but it is, nonetheless, a system of knowledge about a social object.

Lynam: Exploring social representations of adapting to climate change using topic modeling and Bayesian networks

This paper presents the second data-intensive analysis of the project. As with Moloney et al., Lynam (2016) draws on SR theory to contextualize his analysis and interpretation. Lynam took 660 micronarratives produced by respondents who were Australian academics or researchers, government employees, or members of the public, and analyzed them using a data analytic technique called topic modeling, which is new to the social representations literature. This is an algorithm-driven data analysis technique that allows large collections of text data to be systematized into topics (probability distributions across words) and documents (probability distributions across topics). The analytic focus is on the meaning of words and topics, not on the authors who produce the words. Lynam then joined the topic modeling analysis with a Bayesian analysis of the relationships among the topics and respondents' answers to questions about their narratives.

Several facets appear in the results that illuminate the social psychological processes in how people (citizens as well as scientists) go about understanding the novel or unfamiliar social object of climate change, and especially the importance of belief and trust, empowerment and guidance, and theories of change in connecting understandings of climate change to behaviors. Although these topics cut across the three groups of participants, they were differentially important to the groups.

An important, general implication from Lynam's analysis is that those researchers who wish to better understand how beliefs and knowledge translate into action, or, more typically, fail to translate into any action, would do well to move away from the standard, tacit, linear models of knowledge and beliefs leading directly to action. Instead, the connections between knowledge/belief and action are more nuanced and interactive, as captured in SR theory. Indeed, some formulations of SR theory do not distinguish between knowledge/belief and action, treating all these concepts (and others, such as attitudes and values) as but aspects of a social representation. That is, these are not discrete, causally related concepts, but rather related, intertwined aspects of the same thing.

\section{Milne: Can sense-making tools inform adaptation policy? A} practitioner's perspective

One of the major aims of the project that has produced the papers in this special feature was to produce insights into how people understand climate adaptation that would be useful for policy makers. The paper by Milne (2015) presents the reactions of a Canadian policy maker to the project, after joining the project late in its life.

Milne paints a context where policy makers struggle to deal with climate change and all its implications for all aspects of all levels of government. Most such policy makers are required to deal with climate change on top of a raft of other, more traditional, often more pressing issues. Some such people are open to insights into climate change from the human and social sciences that will help them do their jobs better, but are necessarily constrained by the need for any science input to be scientifically rigorous and, preferably, not couched in the qualifications and uncertainties that habitually comfort most scientists. Given that background, Milne had high hopes that this project might demonstrate a powerful new way for policy makers to grapple with the complexities of human constituents.

In her frank assessment, she concludes that the project's findings are unlikely to have any direct policy impact (although her paper was written before all papers in the special feature were developed or completed). That is not to say they lack value, though. The 
findings offer good direction while lacking specific details, and they open policy makers' minds to the many different ways that climate change can be understood and responded to. The project has also forged new relationships between policy makers and researchers, creating connections for future policy influence.

Milne concludes with three clear recommendations that are likely to be germane to any researchers wishing to engage with policy makers and with policy change. First, she concludes, researchers must acknowledge and accept that policy makers are not (yet) attuned to the finer points of social science. Second, researchers have to be clear when communicating with policy makers about the meaning of their terms and concepts, in this case about "narrative." And finally, for research to influence policy, policy makers need not necessarily be involved in all aspects of research.

These three recommendations, when joined with Milne's earlier points, suggest to us that research and policy can be closely intertwined, but that researchers must consider closely with policy makers at the outset of projects what sort of policy impact is envisaged and how will policy makers be involved in the different stages of a research project. Of course, there is a fine line here between policy makers being engaged with research, on the one hand, and maintaining the independence of the research from policy makers, on the other.

\section{WHAT WE HAVE LEARNED}

In undertaking the research and publication of the papers in this special feature much has been learned. As is so often the case however, what is learned serves to bring out of the shadows how much is not known. In this last section we highlight some of what we have learned, but mostly note how much more we now know to be in the shadows!

One critical lesson from this work is that framings are (almost) everything and everywhere. Although not a new insight, particularly across many dimensions of the social sciences (Goffman 1974, Tversky and Kahneman 1981, Edelman 1988, Schön and Rein 1994, Bovens and Hart 1996), the effects of theoretical, methodological, or pragmatic framing can be seen throughout the articles of this special feature. Here are a few examples:

Both Lynam (2016) and Lynam and Fletcher (2015) demonstrate how different framings, by individuals and society, of climate change or adaptation to climate change differentially orient people to action. For example, those who framed climate change as a natural phenomenon tended to feel disempowered (Lynam and Fletcher 2015) and tended not to do anything other than seek guidance as to what to do (Lynam 2016).

But the effects of different framings extend far beyond individual respondents in the surveys. Milne (2015) highlights how different policy perspectives (framings) differentially enable and constrain policy analysts' engagement with complex problems such as climate change: how they are thus oriented to defining problems and finding solutions and how receptive they might then be to the type of analyses presented in this special feature. Lynam and Fletcher (2015) adopt a framing and theoretical model, the transtheoretical or stages-of-change model (Prochaska and DiClemente 1986), which is oriented to individuals as adaptors and hence leads to adaptation solutions oriented to individuals. In contrast Moloney et al. (2014) and Lynam (2016) adopt a social framing from social representations theory, which suggests more socially oriented solutions, e.g., communication campaigns.

The methods we as scientists use, the theories that guide us, our representations of what was going on, all orient what was done and how it was interpreted. What does this mean for "crisp little gems of peer guaranteed truth?" Whose truth? To what extent is what we find contingent on the theories and methods we use? This is of course an old debate in the social sciences and in part stimulated the emergence of grounded theory (Glaser and Strauss 1973, Glaser 1993, Strauss and Corbin 1997, Corbin and Strauss 2008) and does not need to be revisited here. The original idea behind this project was to provide multiple perspectives on adaptation to climate change: different theories and methods applied to the different perspectives of diverse individuals reflected in the data. But as Milne (2015) so clearly points out, what are we to do with all these perspectives when a great deal of policy and of society is oriented to a single, clear, and certain truth? How does a scientific endeavor that appreciates the effects of framing engage with a society that does not? Is it any wonder that society so readily accepts simplistic framings and results when the alternative can be so daunting and confusing?

A second striking lesson has been the richness of the data produced using respondent-interpreted narrative. Although implementing only a few of the originally intended theoretical and analytical options, the papers in this special feature have all found remarkable depth and breadth in the data while only scratching the surface of the analytical options.

Despite this richness only Lynam appears to have continued using the approach for other projects (Krentel et al., in press). In part this may be attributed to the expense and technical limitations of working with SenseMaker (Lynam and Fletcher 2015). Or perhaps it is related to questions about what exactly the micronarratives are (narrative or opinion?) and what purpose do they serve (Milne 2015). The nature and purpose of micronarratives in this approach has not been clearly articulated. But we suspect a dominant reason for the slow uptake of respondent-interpreted narratives as an approach to working with social phenomena may be that the approach of collecting situated narratives that respondents interpret is not yet part of the conventional framing of how to collect social data.

Solving the problem of working with SenseMaker is not that difficult; standard data collection tools can be used to the same effect. Copyright restricts use of some of Cognitive Edge's data collection devices, e.g., triads and stones, but our experience with these is that they add little to the richness of the data from an analytical perspective.

The critique of what the narratives are is important. Milne (2015) questions what the micronarratives were. One answer is that the narratives serve to bring into working memory (and, as Barsalou suggests [Barsalou et al. 2003, Barsalou 2008], into the motor and control functions of the body) direct experiences or representations in response to the prompt. The articulation of these experiences or representations (by the respondent) as written or verbal material is expected therefore, to capture only salient parts. What is fundamentally important is that through having the experience in working memory the subsequent interpretation of the experience is expected to be more informative 
as different elements of the experience are re-enacted (Barsalou et al. 2003, Barsalou 2008). None the less, as far as we can tell, there has not been a great uptake in academia of SenseMaker or the fully integrated qualitative / quantitative survey tools of which SenseMaker is an example

We have learned a good deal about collective learning through the scientific and hence peer review process. As was noted in the introduction, we started out with 12 nascent stories to tell. Four made it to the end with two of these very different to how they started out. This is quite a dramatic attrition rate of what were, for the most part, innovative and interesting perspectives on the data. We come back to the question of how does a scientific endeavor that appreciates the effects of framing and multiple perspectives engage with a scientific community that almost by definition has to adopt and maintain clear disciplinary boundaries? As with the previous framing of this question we do not have answers: we acknowledge, fully accept, and have been enriched by the rigorous peer review process that has been so integral to the journeys of these stories. Many people have contributed a great deal to improving the papers that made it to the end. Papers that we hope will make a small contribution to the emerging representation of how society makes sense of adaptation to climate change.

Last, were someone to ask us what theory and methods to use for a similar endeavor we would unhesitatingly recommend the combination of social representations theory and tools that are reflected in this special feature. Whether to better understand how people make sense of, and act in relation to, complex phenomena or to identify interventions to change outcomes, these tools and SR theory provide a robust, powerful, and salient framework.

Responses to this article can be read online at: http://www.ecologyandsociety.org/issues/responses. $\mathrm{php/8886}$

\section{LITERATURE CITED}

Augoustinos, M., I. Walker, and N. Donaghue. 2014. Social cognition : an integrated introduction. Third edition. SAGE, Los Angeles, California, USA.

Barsalou, L. W. 2008. Grounded cognition. Annual Review of Psychology 59:617-645. http://dx.doi.org/10.1146/annurev. psych.59.103006.093639

Barsalou, L. W., W. K. Simmons, A. K. Barbey, and C. D. Wilson. 2003. Grounding conceptual knowledge in modality-specific systems. Trends in Cognitive Sciences 7:84-91. http://dx.doi. org/10.1016/S1364-6613(02)00029-3

Bovens, M. A. P., and P. Hart. 1996. Understanding policy fiascoes. Transaction Publishers, Piscataway, New Jersey, USA.

Corbin, J., and A. Strauss. 2008. Basics of qualitative research: techniques and procedures for developing grounded theory. Third edition. SAGE Publications, Los Angeles, California, USA. http://dx.doi.org/10.4135/9781452230153
Davis, W. 1996. One river: explorations and discoveries in the Amazon rain forest. Simon \& Schuster, New York, New York, USA.

Edelman, M. 1988. Constructing the political spectacle. University of Chicago Press, Chicago, Illinois, USA.

Glaser, B. G. 1993. Examples of grounded theory: a reader. Sociology Press, Mill Valley, California, USA.

Glaser, B. G., and A. L. Strauss. 1973. The discovery of grounded theory: strategies for qualitative research. First paperbound edition. Aldine, Chicago, Illinois, USA.

Goffman, E. 1974. Frame analysis: an essay on the organization of experience. Harvard University Press, Cambridge, Massachusetts, USA.

Jones, N. A., H. Ross, T. Lynam, and P. Perez. 2014. Eliciting mental models: a comparison of interview procedures in the context of natural resource management. Ecology and Society 19 (1):13. http://dx.doi.org/10.5751/es-06248-190113

Jones, N. A., H. Ross, T. Lynam, P. Perez, and A. Leitch. 2011. Mental models: an interdisciplinary synthesis of theory and methods. Ecology and Society 16(1):46. [online] URL: http:// www.ecologyandsociety.org/vol16/iss1/art46/

Krentel, A., R. Damayanti, C. R. Titaley, N. Suharno, M. Bradley, and $\mathrm{T}$. Lynam. In press. Improving coverage and compliance in mass drug administration for the elimination of LF in two 'endgame' districts in Indonesia using micro narrative surveys. PLOS Neglected Tropical Diseases.

Kurtz, C. F., and D. J. Snowden. 2003. The new dynamics of strategy: sense-making in a complex and complicated world. IBM Systems Journal 42:462-483. http://dx.doi.org/10.1147/sj.423.0462

Leviston, Z., and I. A. Walker. 2011. Baseline survey of Australian attitudes to climate change: preliminary report. CSIRO, Canberra, Australia.

Lynam, T. 2016. Exploring social representations of adapting to climate change using topic modeling and Bayesian networks. Ecology and Society 21(4):16. http://dx.doi.org/10.5751/ ES-08778-210416

Lynam, T., and K. Brown. 2011. Mental models in humanenvironment interactions: theory, policy implications, and methodological explorations. Ecology and Society 17(3):24. http://dx.doi.org/10.5751/es-04257-170324

Lynam, T., and C. Fletcher. 2015. Sensemaking: a complexity perspective. Ecology and Society 20(1):65. http://dx.doi. org/10.5751/es-07410-200165

Lynam, T., R. Mathevet, M. Etienne, S. Stone-Jovicich, A. Leitch, N. Jones, H. Ross, D. Du Toit, S. Pollard, H. Biggs, and P. Perez. 2012. Waypoints on a journey of discovery: mental models in human-environment interactions. Ecology and Society 17(3):23. http://dx.doi.org/10.5751/es-05118-170323

Mathevet, R., M. Etienne, T. Lynam, and C. Calvet. 2011. Water management in the Camargue Biosphere Reserve: insights from comparative mental models analysis. Ecology and Society 16 (1):43. [online] URL: http://www.ecologyandsociety.org/voll6/ iss $1 / \operatorname{art} 43 /$ 
Milne, K. M. G. 2015. Can sense-making tools inform adaptation policy? A practitioner's perspective. Ecology and Society 20(1):66. http://dx.doi.org/10.5751/ES-06791-200166

Moloney, G., Z. Leviston, T. Lynam, J. Price, S. Stone-Jovicich, and D. Blair. 2014. Using social representations theory to make sense of climate change: what scientists and nonscientists in Australia think. Ecology and Society 19(3):19. http://dx.doi. org/10.5751/es-06592-190319

Moscovici, S. 1984. The phenomenon of social representations. Pages 3-69 in R. M. Farr and S. Moscovici, editors. Social representations. Cambridge University Press, Cambridge, UK.

Prochaska, J. O., and C. C. DiClemente. 1986. Toward a comprehensive model of change. Pages 3-27 in W. R. Miller and N. Heather, editors. Treating addictive behaviors: processes of change. Plenum, New York, New York, USA. http://dx.doi. org/10.1007/978-1-4613-2191-0 1

Prochaska, J. O., C. C. DiClemente, and J. C. Norcross. 1992. In search of how people change: applications to addictive behaviors. American Psychologist 47(9):1102-1114.

Sarbin, T. R. 1986. Narrative psychology: the storied nature of human conduct. Praeger, New York, New York, USA.

Schön, D. A., and M. Rein. 1994. Frame reflection: toward the resolution of intractable policy controversies. BasicBooks, New York, New York, USA.

Snowden, D. J., and M. E. Boone. 2007. A leader's framework for decision-making. Harvard Business Review November:1-9.

Stone-Jovicich, S. S., T. Lynam, A. Leitch, and N. A. Jones. 2011. Using consensus analysis to assess mental models about water use and management in the Crocodile River Catchment, South Africa. Ecology and Society 16(1):45. [online] URL: http://www. ecologyandsociety.org/vol16/iss1/art45/

Strauss, A., and J. Corbin. 1997. Grounded theory in practice. SAGE, Thousand Oaks, California, USA.

Tversky, A., and D. Kahneman. 1981. The framing of decisions and the psychology of choice. Science 211:453-458. http://dx.doi. org/10.1126/science. 7455683

Weick, K. E. 1995. Sensemaking in organizations. SAGE, Thousand Oaks, California, USA. 